\title{
La invisibilidad del otro. Eutanasia y dignidad humana*
}

\author{
ANDRES OLLERO \\ Catedrático de Filosofla del Derecho, \\ Universidad Rey Juan Carlos (Madrid)
}

SUMARIO:

Entre clericalismo y laicismo.

Dar al derecho lo que es del derecho y a la moral to que es de la moral.

Sanidad y disponibilidad de la vida: entre dignidad y autonomia.

Por paradójico que pueda resultar, pocas realidades nos obligan tanto como la muerte a interrogarnos sobre el sentido de nuestra vida. Pocas realidades como la muerte se ven también, en consecuencia, a la hora de intentar darles sentido, tan marcadas por la entrada o no en juego de una concepción inmanente o transcendente de la propia vida.

Como andaluz, la reflexión sobre la muerte no figura entre mis pasatiempos preferidos. Ello no ha sido óbice para que me haya visto convertido, repetidamente, en obligado protagonista de debates sobre un problema tan adentrado en este contexto como el del tratamiento jurídico de la eutanasia. Así ha sucedido a lo largo de mis diecisiete años de trabajo parlamentario ${ }^{1}$, tarea a la que, en legítimo ejercicio de mi autonomía, pondré voluntariamente fin dentro de dos semanas, sin esperar 
siquiera a que finalice la presente Legislatura. Y lo haré no sin suscitar cierta sorpresa, ya que ningún elemento patológico o desfavorable parece justificarlo; salvo el posible prurito -no sé si ético o meramente estético- de desmentir la idea muy difundida en mi país de que los políticos son especie tan adosada al cargo público que habría que recurrir al agua caliente - sin excluir un posible refuerzo judicial- para lograr despegarlos de ellos.

Lo dejo sentado de antemano, consciente de que con ello no me coloco en una situación particularmente favorable para poner en cuestión que alguien, en no menos legítimo ejercicio de su autonomía, estime contar con sobrada justificación ética -e incluso estética- para despegarse de su propia vida, cuando ésta patológicamente arruinada sólo parezca ya ofrecerle un horizonte difícilmente soportable.

La autonomía personal, enraizada en la dignidad humana, acompaña habitualmente como ingrediente inseparable al ejercicio de nuestras más decisivas libertades. Cuando hablamos de libertad sindical, nos estamos refiriendo tanto a nuestro derecho a afiliarnos a una determinada central como al, no menos relevante, de optar por mantenernos al margen de todas ellas ${ }^{2}$. Mi libre derecho a la participación política y a acceder en condiciones de igualdad al desempeño de cargos públicos ${ }^{3}$ no lo he ejercitado más hasta ahora, encabezando hasta cinco veces una lista electoral, de lo que lo ejercitaré dentro de once días, al dar opción al siguiente de los candidatos de la lista del partido para que ocupe mi escaño. Hablar en términos jurídicos de libertad religiosa incluirá también, junto a la garantía de no verse obligado a pronunciarse sobre el particular ${ }^{4}$, la de optar por no adherirse a ninguna confesión, y así sucesivamente...

No faltan, sin embargo, casos o circunstancias en los que el ejercicio de un derecho parece convertirse en deber, incluso enojoso, para su titular o para los situados en su entorno. Así ocurre cuando el derecho a la educación, durante los años precisos para recibir determinadas enseñanzas, se convierte en obligatorio ${ }^{5}$; también para buena parte de la po- 
blación gitana, que ve sin claro fundamento rechazado su deseo de evitar que sus hijas, al llegar a la pubertad, se vean encuadradas en centros públicos de enseñanza mixta. No somos, pues, libres de recibir o no determinado nivel de instrucción, ni siquiera dando entrada al multiculturalismo más políticamente correcto.

La paradójica figura del 'derecho irrenunciable' encuentra su más arquetípico ejemplo cuando nos referimos al ejercicio mismo de la liber$\operatorname{tad}^{6}$. Un irónico film español giraba en torno a la sublime decisión de venderse como esclavo, asumida por un erudito Ordinario de Derecho Romano sometido por la jubilación al presunto disfrute de una famélica pensión. Si tuviera que opinar al respecto alguien tan celoso de la libertad como John Stuart Mill, diría que "el fundamento de una tal li.* mitación del poder de voluntaria disposición del individuo sobre sí mismo es evidente": "el principio de libertad no puede exigir que una persona sea libre de no ser libre. No es libertad el poder de renunciar a la libertad"?.

¿Cabría atribuir al derecho a la vida similar condición? Alguien como Thomas Hobbes parecería suscribirlo: "hay en la naturaleza humana dos anhelos fundamentales: uno dimana de la codicia natural, y lleva a cada uno a reclamar para sí solo el uso de las cosas comunes; el otro procede de la razón natural, e incita a los hombres a buscar el medio de evitar la muerte violenta, que consideran el peor de los males naturales". Y, a fuer de empírico, no dejará de añadir: "esa inclinación es tan natural como la que lleva a la piedra a caer"9. Si la obediencia al derecho cobra, para él, aire racional es en la medida en que se muestra capaz de garantizarnos que nadie nos va a matar.

Cabría aducir que está pensando en una muerte no deseada, ajena absolutamente a toda decisión autónoma. Sin embargo, el parangón pétreo sugiere también que tal situación le resulta, por irracional, poco concebible. Si alguien deseara la muerte ello podría más bien constituir un bien elocuente indicio de su autonomía es tan gravemente deficitaria como para verse invalidada a la hora de justificar éticamente deci- 
sión alguna. Podría ser también esa presunción de deficitario consentimiento, más que lo contrario, la que lleve a establecer la irrelevancia jurídica de la tentativa de suicidio ${ }^{10}$, o a considerar sin mayores dudas como un héroe al servidor público que arriesgó su vida para hacerla inviable.

Se trata de un debate circunscrito hasta aquí a un marco de mera ética racional, que no es precisamente el que tiende hoy a acompañarlo, de modo muy particular en países latinos. En ellos no parece imaginable hablar cinco minutos sobre la eutanasia sin que lo religioso, por activa o por pasiva, se adueñe del escenario ". En el caso español, el debate parece desplazarse así del artículo 15 de la Constitución ${ }^{12}$, que protege la vida humana, al vecino y ya citado artículo 16 , que garantiza la libertad ideológica y religiosa ${ }^{13}$. No resulta por ello extraño que en algún grupo parlamentario se ponga en estos casos en ejercicio una nada habitual libertad de voto entre sus diputados, o incluso que desde algunos otros se anime a los del grupo mayoritario a votar "en conciencia"l4.

Esta, sin duda altruista, invitación merece quizá alguna breve reflexión. Es obvio que no será lo mismo ocuparnos de nuestro problema desde una perspectiva jurídica, deudora de puntos de partida políticos, que desde una perspectiva estrictamente moral, más o menos alimentada por raíces religiosas.

\section{ENTRE CLERICALISMO Y LAICISMO}

No parece que al animar a votar en conciencia, se estuviera sugiriendo explícitamente que el previsible respeto de la disciplina de voto dentro de su grupo parlamentario obligara al diputado a sumirse en la inconsciencia. No faltarían, por otra parte, razones éticas para considerar loable que los diputados asuman voluntariamente la posición de su grupo $^{15}$. No en vano hay quien rechaza, en nombre del 'liberalismo político', que alguien (incluso un ciudadano de a pie) actúe convencido de 
que "votar es un asunto privado, o incluso personal"; es decir, "que la gente puede votar según lo que considera correcto y verdadero, directamente de acuerdo con sus convicciones comprehensivas y sin tener en cuenta las razones públicas"; al menos "a la hora de votar sobre asuntos constitucionales esenciales y sobre cuestiones de justicia básica"16. Aspectos estos que en principio no sería temerario entender, al menos en teoría, más equilibradamente custodiados por partidos y grupos políticos que por el leal saber y entender de cada cual.

La invocación al voto en conciencia parecería remitir a un ámbito moral y privado, en el que el diputado habría de recobrar un adecuado fundamento para su decisión, que indebidamente podría sustraerle la disciplina de su grupo. El argumento no parece muy brillante, lo que invita a pensar que se nos remite más bien a un ámbito de moralidad pública, que se da por universalmente compartido. Se lo contrapone paradójicamente a los criterios emanados de unos partidos y grupos políticos de los que cabría esperar sirvieran de privilegiado cauce de expresión de esa misma razón pública, destinada a prevalecer sobre las no menos morales y legítimas opciones privadas. Aun así sería precisa alguna otra pieza adicional para solventar al fin tan barroco desbarajuste: determinados partidos habrían perdido su presumible vinculación con esa razón pública; a los ojos, al menos, de quienes los consideran secuestrados por criterios de procedencia religiosa que nada tendrían que ver con ella. Se parte de la sospecha de que habrían decidido marginarla en aras del rechazable designio de imponer determinadas (y, en este caso, 'privadas') convicciones a los demás.

Es de temer que con todo ello se está generando una viciosa circularidad. Se parte implícitamente del convencimiento de que la religión es asunto privado. Se constata que determinados ciudadanos, de los que cabe fundadamente sospechar alberguen convicciones religiosas, discrepan en cuestiones de interés público de otros, que convierten a su vez el no tenerlas en rasgo relevante de su propia identidad. Se acaba dando por supuesto que las convicciones de éstos son 'públicas', mientras las 
de aquéllos se ven degradadas a meramente privadas. El círculo se cierra: un argumento - todo lo discutible que se quiera pero obviamente público- resulta expulsado de ese ámbito por su presunta connotación religiosa ${ }^{17}$. Se produce así una clara ruptura de la simetría en el discurso, similar a la que ha llevado a más de algún alemán a quejarse de la peculiar inquisición a que se ven sometidas sus opiniones sobre problemas bioéticos, presuntamente lastradas por cierta mala conciencia histórica ${ }^{18}$. Confinar el alcance de un concepto de lo lícito o ilícito a un ámbito meramente geográfico parece, en efecto, tan poco razonable como darlo por configurado con un alcance meramente confesional ${ }^{19}$.

Tal circularidad podría explicar la existencia de una doble y dispar apelación a la conciencia. Por una parte, se rechaza que decisiones políticas puedan encontrar fundamento en la propia conciencia (entendida en clave a la vez moral y religiosa ${ }^{20}$ ), ya que ello implicaría imponer las propias convicciones a los demás. Por otra, se invita a votar en conciencia (entendida ahora en clave a la vez política y racional). Quedarían aun así dos misterios por resolver: cómo sería posible asumir una conciencia pública sin aferrarse a alguna convicción personal y, si ello no fuera posible, cómo explicar que su posterior conversión en norma vinculante para los demás no implique en este caso imposición alguna.

Desde el "liberalismo político" que nos sirve de referencia se nos apuntan dos elementos tan diversos como significativos, sobre todo si los transplantamos de su solar norteamericano a pagos latinos.

Se nos propone, en primer lugar, una continua equiparación de lo religioso con lo filosófico o moral, como posibles trasfondos de las decisiones públicas $^{21}$. Se descarta, por consiguiente, la viabilidad de una solución drástica: atribuir al derecho una función meramente procedimental, capaz de garantizar una total asepsia en el ámbito de lo público y relegar a lo privado las preferencias éticas de cada cual ${ }^{22}$. Se invita más bien a una igualdad de trato, excluyendo el frecuente uso maniqueo del término 'convicciones', según el cual sólo el que se sirve de fuentes o motivaciones de origen religioso tendría en sentido propio 
convicciones, y podría acabar en consecuencia imponiéndolas; los que - sin duda, no menos convencidos- resultan sólo deudores de 'ideas' filosóficas o morales no asumirían propiamente convicciones susceptibles de ser impuestas.

Se nos podría quizá añadir que las ideas, a diferencia de las convicciones, se argumentan; pero tal sugerencia puede acabar resultando doblemente falaz. No resulta ya hoy, felizmente, concebible que en una democracia pluralista alguien pretenda dar curso público a propuesta alguna sustituyendo su obligada argumentación civil con fundamentalistas argumentos de autoridad de procedencia religiosa. Por el contrario, cuando la argumentación sí desaparece obligadamente, tras convertirse en superflua, es cuando en plena caza de brujas se rechaza de antemano una opción por su mero parentesco religioso, sin entrar siquiera a debatir la fundamentación no 'autoritaria' propuesta.

Sin duda este primer elemento que venimos analizando podría marcar la diferencia cultural entre una sociedad multiconfesional como la norteamericana, nacida de la exclusión de toda guerra de religión, y sociedades en las que históricamente el clero parece haber ejercido la rara capacidad de convertirse en punto de referencia, activo o pasivo, de todo conflicto social imaginable. El segundo elemento puede brindarnos alguna pista sobre tan peculiar fenómeno histórico.

Dentro del aire discursivo que acompaña a los modelos neocontractualistas, nuestro problema parece plantearse en el ámbito del saber. Todos los contratantes aportan lo que saben, y en alguna sede deben haberlo aprendido. Intentar privilegiarlos o descalificarlos por sus fuentes de conocimiento, no sólo haría imposible cualquier "velo de la ignorancia"23 sino que daría vía libre a la más neta discriminación.

Para algunos la fe, en su afán por aportar una respuesta última y omnicompresiva al sentido de la existencia, se presenta como un 'saber más'. Nada cabe objetar a que la jerarquía de turno les ilustre sobre su efectivo alcance ${ }^{24}$, que no tiene por qué exigir confrontación ni rivalidad alguna con el saber cívico en el que ha de fundarse el diseño del 
ámbito público, sobre el que no es descartable llegue a influir. Menos aún, si tal fe viene asumiendo desde hace siglos (baste recordar a Grocio) la existencia de un orden ético natural accesible a la razón sin necesidad de suplementos sobrenaturales.

En todo caso, ese don que podría llevar a saber más en el ámbito personal no atribuye en modo alguno un derecho a 'saber demasiado'; de él se serviría quien por su fe se considerase eximido de recurrir a una argumentación racional, al realizar sus propuestas en el ámbito social. $\mathrm{Ni}$ el clericalismo fundamentalista, de los que se empeñan perezosamente en saber tanto como para que les resulte ocioso dar razón de ello, ni el anatema laicista, que convierte la privatización de lo religioso en pre-argumento de infalible éxito, encontrarían en este ámbito campo de juego alguno.

El segundo elemento al que habíamos aludido nos traslada del hipotético ámbito del saber al escenario práctico del poder: "un entendimiento continuo y compartido sobre una doctrina comprehensiva religiosa, filosófica o moral sólo puede ser mantenido mediante el uso opresivo del poder estatal"25. El panorama cambia si se da por hecho que esto es lo que históricamente habría ocurrido. En tal caso, aferrarse al juego formal del imperativo de la no discriminación no haría sino perpetuar la desigual situación resultante en perjuicio de determinados grupos de ciudadanos, como ocurre en otros ámbitos en los la discriminación se muestra particularmente arraigada ${ }^{26}$. A la vez, todo intento de restablecer compensatoriamente una situación propiamente neutral conllevará el inevitable riesgo de adentrarse en una discriminación inversa, generando incluso la injustificada neutralización del grupo mayoritario.

Descartada la posibilidad de una neutralidad meramente procedimental en el ámbito público, sí parece exigible una "neutralidad de propósitos", por la que "el Estado debe abstenerse de cualquier actividad que favorezca o promueva cualquier doctrina comprehensiva particular en detrimento de otras, o de prestar más asistencia a quienes la abracen". Ello no podrá impedir, en todo caso, que las decisiones públicas 
acaben teniendo "importantes efectos e influencias en la selección de las doctrinas comprehensivas duraderas y capaces de ganar adeptos con el transcurso del tiempo", por lo que resultaría "inútil tratar de compensar esos efectos e influencias, o incluso tratar de averiguar, con fines políticos, su alcance y su profundidad"27.

La bien intencionada consecuencia sería garantizar un espacio de argumentación cívica que descarte tanto el clericalismo, al excluir todo argumento de autoridad, como un laicismo que intentara inquirir discriminatoriamente sobre la genealogía de los argumentos propuestos, admitiendo sólo aquéllos filosóficos y morales en los que no cupiera detectar influjo religioso alguno.

DAR AL DERECHO LO QUE ES DEL DERECHO Y

A LA MORAL LO QUE ES DE LA MORAL

Aun pacificada esa controvertida neutralidad, presuntamente exigida por una argumentación civil en el diseño de lo público, resta un problema de particular relevancia a la hora de abordar el debate sobre la eutanasia. Asumida - al margen de cualquier fundamentalismo integrista- la autonomía de lo temporal, queda por dilucidar qué exigencias habría que considerar remitidas a la legítima concepción de la vida buena que cada ciudadano tenga a bien privadamente suscribir y cuáles habrían de integrar el ámbito de lo públicamente vinculante.

Las soluciones simples ofrecen una ventajosa facilidad, pero con el previsible costo de acabar resultando simplistas. Tal ocurriría si establecemos solemnemente que la moral debe regir la vida privada y el derecho la pública. Semejante obviedad no sólo reclama notables matices - para que no llegue a descartarse una posible 'inmoralidad pública', o la existencia de unas 'responsabilidades políticas"28 meta o prejurídicassino que nos exige formular un juicio moral, sin el que paradójicamente no cabe establecer la frontera entre obligaciones morales y jurídicas. 
A la hora de formular tal juicio rebrota el ya aludido debate sobre el posible carácter irrenunciable del derecho a la vida. Es fácil imaginar la respuesta moral si se considera la vida como un don recibido de la divinidad, que estaríamos destinados a administrar, pero del que no podríamos libremente disponer ${ }^{29}$. No menos fácil resulta dictaminar que tal planteamiento desborda los límites de una argumentación civil; se adentra en un posible saber-más, que no ahorraría el esfuerzo argumental preciso para convencer a los que, en ejercicio de similar derecho de libertad, se conforman modestamente con un saber-menos. Personalmente debo reconocer mi incapacidad para añadir argumentos civiles que, desde una perspectiva estrictamente moral, justifiquen la imposibilidad de disponer de la propia vida; muy distinta sería, como se verá, mi actitud si la cuestión se me propone en un contexto propiamente jurídico.

Si se admite que la autonomía personal, exigida por la dignidad humana, incluye la posibilidad de disponer de la propia vida, cualquier intento de coartarla por vía jurídica aparecerá a primera vista como fruto de un rechazable "paternalismo'30. Por recurrir a un pasaje clásico, aunque no explícitamente referido a nuestro problema: "nadie puede ser obligado justificadamente a realizar o no realizar determinados actos, porque eso fuera mejor para él, porque le haría feliz, porque, en opinión de los demás, hacerlo sería más acertado o justo"31. Pero la cuestión se complica porque lo que nos estamos planteando no es la viabilidad jurídica del suicidio sino la de la eutanasia, que incluye por definición la intervención de un tercero ${ }^{32}$. Es la acción de éste la que acabaría resultando o no jurídicamente relevante, obligando a plantear hasta tres cuestiones: si debería poder llevarla a cabo de modo jurídicamente lícito, si quien se la solicita sería titular de un derecho a requerirla y si habría, en consecuencia, obligación jurídica de realizarla ${ }^{33}$.

La respuesta no será la misma si reconocemos al enfermo la mera posibilidad de poner fin a su vida - como un 'agere licere' jurídicamente irrelevante- que si lo consideramos titular de un derecho a la muerte. 
Más allá de la difundida idea de que tenemos derecho a todo lo no prohibido, muchas acciones nos resultarán permitidas sin que ello nos atribuya el título preciso para requerir del ordenamiento jurídico amparo a la hora de llevarlas a cabo, eliminando los obstáculos que se les opongan ${ }^{34}$. Dar por hecho que bastaría constatar la existencia de un deseo subjetivo al que quien lo experimenta confiere particular importancia, para reconocer dicho título y generar de inmediato un deber de un tercero $^{35}$, exigiría partir de una armonía preestablecida entre deseos propios y ajenos. Parece preciso asumir jurídicamente una determinada teoría de lo justo que vaya más allá de la convicción de que se tiene derecho a todo lo que se desea con suficiente vehemencia.

Cuando se propone una legalización de la eutanasia se ha abandonado, pues, el mero rechazo de una intervención paternalista para esgrimir, de modo más o menos consciente, un auténtico derecho a morir, que podría llegar a exigir la obligada colaboración de terceros. No es por ello extraño que en más de una de las propuestas legales que venimos comentando vuelva a escena una apelación a la conciencia; pero esta vez para admitirla como motivo de objeción frente a un deber jurídico. No sólo hemos pasado de la mera constatación de un lícito ámbito de libertad individual al reconocimiento de un derecho, sino que éste se acaba configurando inevitablemente como un derecho-prestación garantizado por los poderes públicos. Por duro que suene, hemos pasado a debatir la posible existencia de un derecho a exigir que otro nos mate, ya que sólo partiendo del deber de matar a otro tiene sentido plantear excepciones por la vía de la objeción de conciencia ${ }^{36}$.

Este cambio de perspectiva podría incluso dar paradójicamente entrada en juego a un encubierto paternalismo 'mortis causa ${ }^{37}$, complicado por el difícil deslinde -ante una enfermedad terminal- entre el consentimiento del paciente y la percepción con que en su propio entorno se vive su enfermedad. Dar por hecho que el paciente no se halla en condiciones de soportar una situación que resulta insoportable para el que la contempla debe entenderse como un loable ejercicio de compa- 
sión o simpatía. Derivar de ello de modo automático la exigencia de una intervención ajena podría constituir una presunción paternalista ${ }^{38}$. Descartar que la contemplación del dolor ajeno, muy especialmente si se trata del de una persona querida, pueda resultar más lacerante aún que sufrirlo en carne propia podría resultar un tanto precipitado.

A la problematicidad del consentimiento del paciente se une así este nuevo elemento, que amenaza con provocar un círculo vicioso a la hora de establecer con nitidez quién acabará ejerciendo en la práctica el presunto derecho en juego. Más que la muerte misma, el problema radical que la ausencia de una dimensión transcendente puede acabar favoreciendo es la imposibilidad de encontrar sentido a la convivencia con el dolor, que pasa a considerarse generador de indignidad ${ }^{39}$. Mientras florecen en nuestra sociedad iniciativas estimuladas por la simpatía compasiva respecto a dolores de lejanos terceros mundos, su inmediatez difícilmente soportable, amenaza con generar un difuso cuarto mundo donde la solidaridad se vuelve ambigua. Resulta socavada la posibilidad de una autodeterminación libre de presiones, porque "cuando el seguir viviendo se reduce sólo a una entre dos opciones legales, todo aquél que imponga a otros la carga de su supervivencia estará obligado a rendir cuentas, a justificarse" $"$; ;in excluir que entren en juego presunciones que invertirían la necesidad de prueba ${ }^{41}$.

Entramos de lleno en ese difícil deslinde cuando se nos habla, por ejemplo, de superar un concepto meramente "biológico" de vida, para pasar a hablar de vida digna o de vida de calidad. Se llegará a dar por hecho que, privada de tal calidad, desaparecería el objeto de un derecho a la vida propiamente dicho ${ }^{42}$; lo que permitiría paradójicamente considerar a la legalización de la eutanasia como la primera piedra de una nueva cultura de la vida ${ }^{43}$. Respecto a un status biológico cabe contar con elementos de referencia de relativa fiabilidad; no parece ocurrir lo mismo con el concepto de calidad de vida, que podría acabar convirtiéndose en soporte y condición de la misma dignidad personal ${ }^{44}$. No es difícil aventurar, y no faltan ya informes elocuentes al respecto, que en buen número de casos serán los otros los que acaben dictaminando so- 
bre el particular; mientras la posibilidad de autodiagnóstico se convierte en estas condiciones extremas en una llamativa excepción ${ }^{45}$.

A la vista de todo ello parece obligado reconsiderar si donde el debate sobre la eutanasia resulta inevitablemente agudo es en el plano moral -en el que las diversas concepciones de la vida buena generarían discrepancias - mientras en el plano jurídico resultaría más fácil su admisión, al aspirar sólo a la garantía de un mínimo ético en el que resultaría menos previsible la controversia. Por el contrario, así como dejé sentado que en el plano de la moral personal no me extraña que alguien, que descarte una dimensión transcendente de la vida, no considere rechazable la conducta de quien movido por la compasión participa en una eutanasia activa, dando por supuesto el consentimiento del paciente, es en el plano jurídico donde, a mi parecer, la situación se invierte.

El derecho une a la modestia de sus aspiraciones - se conforma, en efecto, con garantizar un mínimo ético- una particular responsabilidad respecto a su logro, que le impulsa a asegurar que la convivencia social no quedará situada bajo mínimos. Esta responsabilidad impedirá, por ejemplo, que el derecho pueda dar por supuesto el consentimiento del paciente, como si se tratase sólo de una variable más de un caso sometido a evaluación moral, para verse obligado a garantizarlo con el grado de certeza que el bien jurídico en juego exige.

La compasión moral permisiva ha de dar paso a una garantía jurídica responsable. Resulta obvio, para empezar, que el presunto derecho a exigir la muerte sería sólo una solución última y desesperada, ante las posibilidades que va ofreciendo una no siempre suficientemente dotada medicina paliativa ${ }^{46}$. Si lo que se aborda es una efectiva legalización de la eutanasia, el debate sobre las garantías exigibles se convierte en obligado punto central de la argumentación ${ }^{47}$.

Podría objetarse que despenalizar la conducta del tercero no implicaría en sentido propio legalizar. Tan obvia distinción dogmático-jurídica no parece sin embargo tener demasiado relevancia práctica, como las alusiones a la objeción de conciencia ya han puesto de relieve. Con ello se pone de 
manifiesto el papel no meramente represivo que reviste toda norma jurídico-penal. Por acudir de nuevo a los clásicos, el propio Hobbes, tras dar por hecho que "lo que no es injusto es justo", constata la nada positiva querencia del "hombre a convertir la costumbre y el ejemplo en norma de sus acciones, de tal modo que se considere injusto lo que por costumbre se ha visto castigar, y justo aquello de cuya impunidad y aprobación se puede dar algún ejemplo, o precedente"48. La norma penal cumple inevitablemente un adicional papel 'normalizador', por lo que su ausencia puede menoscabar la garantía de los bienes jurídicos antes protegidos; dado que en la medida en que deja de prohibirse una conducta es lógico que pase a reproducirse. Similar objeción cabe oponer a los bienintencionados intentos de postular una neutralidad jurídicopenal, mediante la configuración de un presunto "espacio libre de derecho" capaz de crear una nueva categoría intermedia distinta de lo prohibido y lo permitido ${ }^{49}$.

No es de extrañar que este factor se halle presente en recientes intentos de abordar, al margen de cualquier apelación a la transcendencia, el futuro de la naturaleza humana. Así ocurre en la obra de Jürgen Habermas, para quien el sometimiento de la protección de lo que llama vida pre-personal a fines terapéuticos de alto rango colectivo produciría una "pérdida de sensibilidad de nuestra visión de la naturaleza humana, que con un 'acostumbramiento' de la mano de tal praxis allana el camino a una eugenesia liberal"50. Estas y otras de sus reflexiones sobre el inicio de la vida humana nos parecen extrapolables a su estadio terminal.

El paralelismo entre el derecho y la sanidad, presente ya en la antigüedad griega, va más allá de su condición de saberes prácticos. Inseparable del derecho es la exigencia de simetría, derivada de su radical exigencia de tratar al otro como un igual. No muy distinto es "ese punto de vista moral del trato no instrumentalizador con una segunda persona" que 
se detecta en la "lógica del sanar". De ahí la preocupación ante la ruptura de la simetría presente en la planificación eugenésica, en la que "lo padres sin sometimiento a consenso deciden sólo con arreglo a sus propias preferencias, como si dispusieran de una cosa". "La libertad propia se vive en relación con algo natural indisponible", a lo que la persona liga su propio origen, de modo que no depende de "otra"; precisamente "el carácter natural del nacimiento cumple el papel conceptualmente exigible de ese comienzo indisponible". Todo ello no implicaría oponerse a la tecnificación porque afecte a una "naturaleza interna". "La crítica vale con total independencia del planteamiento de un orden jurídico-natural u ontológico que pudiera 'transgredirse' desaforadamente"

Sin duda, si se centra la mirada en la autodeterminación del enfermo, al quedar marginada la presencia activa del otro, haría innecesaria toda simetría al presentar la eutanasia como un mero acto de renuncia personal. Esta 'invisibilidad del otro' lleva a plantearla como un dilema entre la libertad personal del enfermo y la imposición heterónoma -paternalista o quién sabe si fundamentalista- de criterios despersonalizados. Una vez más el juicio moral se mostrará más propicio a asumir este enfoque que una actitud jurídicamente responsable.

Para el derecho resulta obligado rescatar la visibilidad del otro en un doble plano. La libertad se inserta en un ámbito de esencial solidaridad $^{52}$, por lo que asistimos en realidad al conflicto entre dos libertades. Ya hemos aludido a la libertad del profesional sanitario, de obligada salvaguardia por la vía de la objeción de conciencia. Pero no es él el único otro invisible, dada la dimensión 'normalizadora' que acompaña a lo jurídico, particularmente en su dimensión sancionadora. Se hace así visible la experiencia ya existente sobre el número de enfermos a cuya vida se ha puesto $\mathrm{fin}^{53}$ sin que hayan llegado a prestar un consentimiento equiparable al que se les habría exigido para reconocer a su conducta efectos jurídicos en cualquier otro ámbito de actividad ${ }^{54}$.

Marginado este nuevo conflicto de libertades, el problema parece reducirse a la garantía del consentimiento del enfermo que solicita la eu- 
tanasia. Si se amplía el ámbito de visibilidad, surge la responsabilidad jurídica de garantizar el consentimiento de otros enfermos que, en similares condiciones de ejercicio de su libertad, no la han solicitado. El conflicto entre el ejercicio de un presunto derecho ajeno a morir y un nada presunto derecho a que no les maten resucita la importancia de garantizar jurídicamente el mantenimiento de una "lógica del sanar", dudosamente compatible con esa capacidad de disponer sobre vidas ajenas no exenta de matices cosificadores.

Por más que no quepa excluir la posibilidad de una autodeterminación real del enfermo solicitante, capaz de satisfacer las exigibles garantías, lo que está en juego no es sólo un número determinado de vidas humanas - que por reducido que llegara a constatarse no cabría considerar 'despreciable'- sino, una vez más, "la estructura de nuestra experiencia moral en su conjunto", en la medida en que el loable logro de "un aumento de la autonomía del individuo" se produjera a costa de "minar la autocomprensión normativa de las personas, que rigen su propia vida y se reconocen mutuamente similar respeto". Su más elocuente consecuencia se plasmaría en la quiebra de la relación de confianza en que el trato entre médico y paciente se desenvuelve. La búsqueda de una solución a casos concretos dignos de piedad podría acabar traduciéndose en el cambio radical de un ámbito de actividad social, como consecuencia inevitable de la conversión de la excepción en norma. El problema, una vez más, consistirá en resolver si la actitud más progresista no consistirá en detectar "un incremento de libertad necesitado de regulación normativa", más que en reconocer jurídicamente "la consolidación de transformaciones que dependen de preferencias no necesitadas de autolimitación alguna"55.

Ello no haría sino reabrir un debate jurídico ya habitual ante este tipo de situaciones límite. Se tiende a identificar la defensa más adecuada de los bienes jurídicos en juego con la promoción de reformas por vía legislativa; mediante una despenalización generalizadora, o incluso mediante una legalización que se limitara a establecer un control del proceso de decisión realizado 'ex post facto'. La alternativa apunta a la apre- 
ciación por vía judicial en cada caso de las atenuantes e incluso eximentes que las circunstancias aconsejen ${ }^{56}$. En paralelo a este debate surgirá también la no menos tópica discusión sobre la conveniencia de evitar una excesiva judicialización de la sanidad, dando mayor protagonismo a protocolos de 'buena praxis' clínica ${ }^{57}$.

En cualquier caso, la presencia inevitable del otro, que acabará asumiendo un notable protagonismo en la consumación de la eutanasia activa, invita a reflexionar sobre la relación entre dignidad y autonomía. Históricamente parece fuera de discusión la primacía de la primera. Es la dignidad de la persona humana la que sirve de fundamento al libre desarrollo de su personalidad. Es la dignidad la que marca al otro un ámbito de intangibilidad, vetando todo intento de condicionamiento heterónomo. Paradójicamente, la progresiva afirmación en el ámbito sanitario del principio de autonomía, centrado en el consentimiento informado, puede acabar invirtiendo esa relación, con consecuencias nada irrelevantes. El reconocimiento efectivo de esa dignidad puede acabar dependiendo de la capacidad de expresar la propia autonomía ${ }^{58}$. Lo digno sería respetar esa autodeterminación, por lo que -'a contrario'- la incapacidad de expresarla dejaría en manos de terceros la apreciación heterónoma de si la calidad de esa vida la hace digna de ser conservada ${ }^{59}$.

No hay duda de que un planteamiento abierto a la transcendencia contaría con argumentos privilegiados para mantener la primacía de la dignidad como fundamento de la autonomía. Pero ello no hace sino resaltar en qué medida el gran desafío actual radica en el logro de una fundamentación laica de esa primacía, como la que se intuye en las propuestas post-iusnaturalistas de Habermas y Rawls. Lo encomiable del intento, y lo cuestionable de sus frutos, nos deben servir a todos de incentivo; también a quienes se sientan responsables de un saber-más que no les puede ahorrar perezosamente el esfuerzo por llegar a argumentarlo en un ámbito de discurso compartible por todos. 
* El autor abordó unas reflexiones sobre el estatuto jurídico del embrión humano, fruto de un estudio en preparación. De ahí que se incluya éste, aún inédito.

1 Sin pretender presentar los debates parlamentarios como un dechado de discurso racional, sí cabe considerarlos significativos del acervo argumental de más frecuente acogida por la opinión pública. Sólo con ese valor de síntoma aludiré a pie de página ocasionalmente a las posturas de los diversos grupos parlamentarios españoles con ocasión del último de estos debates: el celebrado ante el Pleno del Congreso de los Diputados el 17 de diciembre de 2002 , con ocasión de las proposiciones de ley presentadas por Izquierda Unida (en adelante IU) y por otros dos partidos: Iniciativa per Cataluña - Els Verds (en adelante IC-EV) y Esquerra Republicana de Catalunya (en adelante ERC) integrados en el Grupo Mixto de la Cámara. Cfr. Diario de Sesiones de Pleno y Diputación Permanente, $\mathrm{n}^{0} 216$, de dicha fecha, págs. 10.901 y ss.

2 Así el artículo 28.] de la Constitución Española (CE), que comienza afirmando que "todos tienen derecho a sindicarse libremente", termina garantizando que "nadie podrá ser obligado a afiliarse a un sindicato".

3 "Los ciudadanos tienen el derecho a participar en los asuntos públicos, directamente o por medio de representantes, libremente elegidos en elecciones periódicas por sufragio universal. Asimismo, tienen derecho a acceder en condiciones de igualdad a las funciones y cargos públicos, con los requisitos que señalen las leyes" (artículo $23 \mathrm{CE}$ ).

4 "Se garantiza la libertad ideológica, religiosa y de culto de los individuos y las comunidades sin más limitación, en sus manifestaciones, que la necesaria para el mantenimiento del orden público protegido por la ley.

Nadie podrá ser obligado a declarar sobre su ideología, religión o creencias" (artículo $16 \mathrm{CE}$ ).

5 "La enseñanza básica es obligatoria y gratuita" (artículo 27.4 CE).
6 "Toda persona tiene derecho a la libertad y a la seguridad. Nadie puede ser privado de su libertad, sino con la observancia de lo establecido en este artículo y en los casos y en la forma previstos en la ley" (artículo 17.) CE). $\mathrm{Su}$ fundamento queda plasmado con anterioridad (en el artículo 10.1 CE) al aludirse a "la dignidad de la persona, los derechos inviolables que le son inherentes, el libre desarrollo de la personalidad", junto al "respeto a la ley y a los derechos de los demás", como "fundamento del orden político y de la paz social".

\section{John Stuart MILL, Sobre la libertad} (traducción al español de Pablo de Azcárate) Madrid, Alianza Editorial, 1979 (2), pág. 190.

8 T. HOBBES De cive, Dedicatoria (citamos por la versión en español de A.Catrysse, con introducción de N.Bobbio, Caracas 1966, pág. 46).

9 T. HOBBES De cive I, 7 (cit. nota 8), pág. 68 . G.PECES-BARBA MARTINEZ rechaza "una posición patrimonialista del derecho a la vida, que sería como un bien disponible por su titular", que "comprendería el de renunciar a su titularidad y a su ejercicio", por considerar que "no cabe que el ejercicio de un derecho tenga como objetivo la desaparición del mismo, lo que acarrea además la imposibilidad de continuar siendo sujeto de derechos $y$ titular de cualquier derecho fundamental" $-L a$ eutanasia desde la Filosofía del derecho en Problemas de la eutanasia (Francisco Javier Ansuátegui Roig coord.) Madrid, DykinsonUniversidad Carlos III, 1999, págs. 15 y 16; también pág. 18. J.ALVAREZ GALVIEZ afirma, por el contrario, que en lo que a la vida se refiere cabe "renunciar al ejereicio del derecho no accediendo al estado de cosas que se protege" - La eutanasia voluntaria autónoma Madrid, Dykinson, 2002, págs. 21-22.

10 Günther JAKOBS señala el paso del suicidio como desafío al orden establecido a la consideración de su protagonista como "alguien que vive en desavenencia consigo 
mismo y que, como consecuencia de esta coyuntura evidentemente desgraciada, realiza un hecho irrelevante desde el punto de vista comunicativo, por lo que no merece ninguna pena"; al basarse esta ausencia de pena en "un presunto conflicto sicológico del cansado de vivir", "no había ninguna razón para dejar sin sanción también al tercero interviniente" -Suicidio, eutanasia y derecho penal Valencia, tirant lo blanch, 1999, págs. 32 y 37. Sobre la impunidad de la complicidad en el suicidio C.ROXIN Tratamiento jurídico-penal de la eutanasia en Eutanasia y suicidio. Cuestiones dogmáticas y de política criminal Granada, Comares, 2001, págs. 25-27.

$11 \mathrm{Si}$ nos remitimos al debate de referencia, IU considera que el " 23 de septiembre de este año hay que conmemorar una fecha histórica" para "la causa de las libertades", dado que "Bélgica, país católico, ha legislado" de modo permisivo sobre el particular; subraya a la vez que "por encima y por debajo de las legítimas creencias religiosas, hay unos valores cívicos en las sociedades democráticas, se está construyendo un consenso social en torno a una nueva cultura de la vida". Para el portavoz socialista (en adelante PSOE), "en un país laico, con vocación de una democracia profunda y de calidad, su primer valor es el de la libertad", por lo que "una vida impuesta contra la voluntad del titular puede estar amparada en valores tan respetables como son los valores religiosos, pero no está amparada en valores constitucionales" (ibidem, págs. 10.902 y 10.910-10.911). También A.RUIZ MIGUEL -en Autonomía individual y derecho a la propia vida. Un análisis filosófico-juridico "Revista del Centro de Estudios Constitucionales" 1993 (14), pág. 136comienza por aludir a la "supervivencia de las influencias religiosas y tradicionales mantenidas por la legislación franquista y actual" a la hora de abordar tal problema.

12 "Todos tienen derecho a la vida y a la integridad física y moral, sin que, en ningún caso, puedan ser sometidos a tortura ni a penas o a tratos inhumanos o degradantes.
Queda abolida la pena de muerte, salvo lo que puedan disponer las leyes penales militares para tiempos de guerra".

13 Así lo hace, por vía civil, I.ALVAREZ GALVEZ para el que, "aunque la decisión de morir no está amparada por el artículo 15 , sí puede verse incluida en el derecho a la libertad ideológica, que únicamente tiene sentido si se entiende no sólo como la libertad de pensar como se desee" sino también "como la libertad de poner en práctica esas ideas", ya que "en caso contrario, sería un derecho vacio, pues de hecho no se puede impedir que cada cual piense como desee" -La eutanasia voluntaria autónoma (cit. nota 9), págs. 25-26 y 194.

14 Para IU "solicitar el voto en conciencia en asuntos como el que estamos tratando y que los grupos políticos se lo permitan a las diputadas y diputados de esta Cámara es un indicador de calidad democrática en el siglo XXI"; también ERC pedirá a todos "su voto en conciencia". IC-EV, por su parte, da por hecho que se trata de "una cuestión que hiere o puede herir sensibilidades, además de afectar a la conciensia de numerosas personas" (ibidem, págs. 10.903, 10.904, 10.905).

15 Aun siendo conscientes, sin duda, de que "los miembros de las Cortes Generales no estarán ligados por mandato imperativo" (artículo 67.2 CE).

16 John RAWIS El liberalismo politico Barcelona, Crítica, 1996, pág. 254.

17 'Tal situación podría producirse también indirectamente cuando se tiende, al configurar el ámbito público, a "eludir las controversias religiosas y filosóficas más profundas"; lo que John RAWLS justificaria "con objeto de no perder la esperanza de conseguir una base para un consenso entrecruzado estable" - $E l$ liberalismo político (cit. nota 16), pág. 184.

18 "Me parece absolutumente equivocado y falaz el argumento de que a los alemanes no nos es lícito abordar determinados temas, a causa de nuestra historia. Si consideramos algo contrario a la ética e inmoral, es precisamente porque es contrario a 
la ética e inmoral siempre y en todo luyar. En las cuestiones éticas fundamentales no existe una geografía de lo lícito o lo ilícito" -Johannes RAU ¿Irá todo bien? Por un progreso a escala humana, epígrafe XIV de su Discurso Berlinés pronunciado en el salón de actos Otto-Braun de la Biblioteca Nacional el 18 de mayo de 2001. Citamos por la versión española publicada en "Nueva Revista" 2001 (76) julio-agosto, pág. 61.

$19 \mathrm{Si}$ se repasa el documento La eutanasia. 100 cuestiones y respuestas sobre la defensa de la vida humana y la actitud de los católicos publicado en 1993 por el Comité Episcopal para la Defensa de la Vida, dependiente de la Conferencia Episcopal Española, es fácil observar que sólo las diez últimas, dedicadas a "La iglesia ante la eutanasia" contienen referencias que desborden una argumentación meramente civil. En las noventa anteriores, aun siendo obvio su contexto doctrinal, sólo se reflejan alusiones indirectas a factores religiosos que no llegan a constituir el centro de la argumentación fundamentadora en cinco: las $16,29,34,40$ y 54 .

20 A.BERISTAIN muestra una tan sorprendente como envidiable convicción al dar por hecha "una distinción elemental entre "moral y "ética', que supongo nadie o casi nadie negará", según la cual "la moral se vincula con los paradigmas de las diversas confesiones religiosas", mientras "la ética se refiere a lo social o cívico o científico" - La eutanasia como excepción "Claves de Razón Práctica" 2000 (102), pág. 29; también pág. 31.

21 "Doctrinas comprehensivas de todo tipo -religiosas, filosóficas y morales-forman parte de lo que podríamos llamar el 'trasfondo cultural' de la sociedad civil", lo que anuncia ya al deseado "pluralismo razonable como un pluralismo de doctrinas comprehensivas, tanto religiosas como no religiosas". No se trata pues de un debate entre convencidos y escépticos: "las luchas más enconadas, segín el liberalismo político, se libran confesadamente por las cosas más elevadas: por la religión, por concepciones filosóficas del mundo y por diferentes doctrinas morales acerca del bien". En consecuencia, "la razón pública no exige a los ciudadanos "erradicar sus convicciones religiosas' y pensar acenca de aquellas cuestiones políticas fundamentales como si partieran de cero, poniendo entre paréntesis lo que en realidad consideran las premisas básicas del pensamiento moral" John RAWLS El liberalismo político (cit. nota 16), págs. 44, 20, 34 y 279.

22 Para John RAWLS "la justicia como equidad no es neutral procedimentalmente. Sus principios de justicia, obvio es decirlo, son substantivos y, por lo tanto, expresan mucho más que valores procedimentales" $-E l$ liberalismo politico (cit. nota 16), pág. 226.

23 John RAWLS El liberalismo político (cit. nota 16), págs. 53 y 344.

24 "En una sociedad democrática, el poder no público" como el que pueda irradiar del mundo universitario o el "ejercido por la autoridad de la iglesia sobre sus feligreses, es aceptado libremente", por lo que "dadas la libertad de culto y la libertad de pensamiento, no puede decirse sino que nos imponemos esas doctrinas a nosotros mismos" -John RAWLS $E l$ liberalismo politico (cit. nota 16), págs. 256-257.

25 "Lo mismo vale, según creo, de cualquier doctrina comprehensiva razonable, filosófica o moral, tanto si tiene carácter religioso como si no lo ticne" -John RAWLS El liberalismo político (cit. nota 16), págs. 67 y 68 .

26 Por ejemplo, el que hemos tenido ocasión de estudiar en Discriminación por razón de sexo. Valores, principios y normas en la jurisprudencia constitucional española Madrid, Centro de Estudios Políticos y Constitucionales, 1999.

27 "Debemos aceptar los hechos de la sociología política de sentido común", sentencia John RAWLS, para quien "podemos distinguir entre neutralidad procedimental y neutralidad de propósitos; pero no hay que confundir esta última con la neutralidad de efectos o influencias" -El liberalismo politico (cit. nota 16), págs. 226 y 227-228. 
28 De ello nos hemos ocupado en

Responsabilidades políticas y Razón de Estado en La criminalidad organizada ante la Justicia (F.Gutiérrez-Alviz dir.) Sevilla, Universidad, 1996, págs. 23-35.

29 Ronald DWORKIN alude a John Locke al evocar este argumento - El dominio de la vida. Una discusión acerca del aborto, la eutanasia y la libertad individual Barcelona, Ariel, 1994, pág. 254.

30 Günther JAKOBS reduce la justificación de la sanción penal de la eutanasia a "la preocupación paternalista de que el peticionante tome por sí mismo la decisión definitiva", de un modo maduro, evitando "el eventual apresuramiento en el modo de tratar la vida propia" -Sobre el injusto del suicidio y del homicidio a petición Bogotá, Lniversidad Externado de Colombia, 1996, pág. 24.

31 John Stuart MILL Sobre la libertad (cit. nota 7). pág. 65. El Tribunal Europeo de Derechos Humanos, al examinar el 29.IV.2002 el caso Pretty contra el Reino Unido, tras recordar (epigrafe 68) que la Convención admite injerencias del Estado en la vida privada, cuando estén "previstas por la ley" y persigan fines legítimos "necesarios en una sociedad democrática", considera (epígrafe 69) que la prohibición del suicidio asistido no vulnera el artículo 8, ya que cumple tales condiciones al perseguir el fin legítimo de preservar la vida $y$ proteger los derechos de otro.

32 Insiste en ello A.M.MARCOS DEL CANO - La eutanasia. Estudio filosófico-juridico Madrid, Marcial Pons - UNED, 199, págs. 173 y 227.

33 V.MENDEZ BAIGES tiene clara la triple respuesta: "el establecimiento de un derecho a morir supone declarar legalmente la facultad de las personas para disponer de la propia vida en ciertas circunstancias; asimismo supone considerar ajustadas a derecho determinadas actuaciones de terceros que ponen fin de forma directa a una vida humana; supone incluso que hay quien puede exigir legalmente ciertas actuaciones a otros para que acaben con su propia vida" -Sobre morir. Eutanasias, derechos, razones, Madrid, Trotta, 2002, pág. 59.

34 La neta distinción entre 'agere licese' y derecho ha sido abordada por el Tribunal Constitucional español hasta en tres sentencias: las 120 y 137 de 1990 y la 11/1991, provocadas con ocasión de huelgas de hambre de miembros del grupo terrorista CRAPO, que esgrimieron su presunto derecho a morir para rechazar la posibilidad de ser alimentados cuando perdieran la conciencia. Las sentencias no reconocen la existencia de ese presunto derecho, aunque lo hacen valorando unas acciones realizadas en un concreto contexto de rebeldía al ejercicio de prerrogativas legítimas de la Administración penitenciaria, lo que las privaría incluso de la mera licitud. Cfr. al respecto nuestro trabajo Derecho a la vida y derecho a la muerte. El ajetreado desarrollo del artículo 15 de la Constitución Madrid, Rialp, 1994. A.RUIZ MIGUEL considera "digna de preocupación" esta posición del 'Tribunal Constitucional, por "su método no liberal, su discutible protección de toda libertad para los que llama 'objetivos no amparados por la ley' $y$ su poco clara concepción sobre la relación entre libertad y derecho" -Autonomía individual y derecho a la propia vida (cit. nota 11), pág. 144. Sus fundamentos jurídicos han sido reiteradamente invocados con posterioridad con motivo de una solicitud de eutanasia, como anota E.PFREZ SANCHEZ la eutanusia voluntaria activa. Consideraciones éticas y jurílicas sobre el 'caso Sampedro' "Claves de Razón Práctica" 1997 (74), págs. 59 y 60 . EI Trihunal Europeo de Derechos Humanos, en el caso Pretty (cit. nota 31) no considera (epigrafe 38) que el derecho a la vida garantizado por el artículo 2 de la Convención pueda interpretarse incluyendo un aspecto negativo, similar al derecho a no asociarse del artículo 11, ya que (epígrafe 39) no cabría, sin distorsionar el lenguaje, inteppretarlo confiriendo un derecho diametralmente opuesto como el derecho a morir. Por todo ello (epígrafe 40) no es posible deducir del artículo 2 un derecho a morir, sea a manos de un tercero o con ayuda de una autoridad pública. 
35 Asume esta postura con particular nitidez I.ALVAREZ GALVEZ, para el que existe un derecho a la muerte, en la medida en que constituye "un estado de cosas deseable y deseado por los individuos en determinadas circunstancias", ya que "tanto la decisión de vivir como la decisión de morir pueden ser manilestaciones autónomas de una persona. Concebido así el derecho a morir, se crean determinados deberes en terceras personas. Desde luego, un deber general de no interferir la decisión autónoma del titular del derecho. $Y$, en segundo lugar, si el acceso al estado de muerte (en los supuestos de eutanasia) es muy importante para los sujetos, un deber de ayudar a acceder a ese dicho estado, impuesto a las personas que, con su omisión, son causa de que ese acceso no sea posible. Con todo, todavía es posible articular una necesaria cláusula de conciencia, en atención al especial carácter del deber $y$ a su incidencia en las convicciones más profundas de las personas" -La eutanasia voluntaria autónoma (cit. nota 9), págs. 22 y 111.

36 Así ocurre en el debate de referencia con la proposición de ley de Ili, que incluye "el derecho de objeción de conciencia del personal sanitario para que libremente también ellos puedan decidir", previendo incluso un "registro cerrado", destinado a evitar que quienes se nieguen a realizar tal actividad en la sanidad pública pudieran hacerlo en la privada. También desde ERC se excluye "que el médico al que sus creencias no le permitan asistir a nadie en este derecho que pretendemos que se reconozca legalmente to haga" (ibidem, págs. 10.902-10.903 y 10.904).

37 Así, por ejemplo, M.GASCON ABELLAN suscribe que "la indisponibilidad de la vida peca de enmascarar un cierto paternalismo", que extiende también a la prohibición del auxilio al suicidio, pero considera justificada la eutanasia realizada "pensando en el bien de la persona que muere" o "entendiendo la muerte como un bien para esa persona" -Problemas de la equanasia "Sistema" 1992 (106), págs. 96, 85 y 86.
38 A.M.MARCOS DEL CANO se pregunta "¿cómo se puede calcular la experiencia de dolor y de placer de los demás? Lo que para un individuo puede ser insoportable, para otro puede ser una razón de vida" - La elutanasia (cit. nota 32), pág. 174. 'También J.M. SERRANO RLIZ-CALDERON Eutanasia y vida dependiente. Inconvenientes juridicos y consecuencias sociales de la despenalización de la eutanasia Madrid, Ediciones Internacionales Universitarias, 200I, pág. 143.

J.BALLESTEROS señala que "la distinción entre vida con valor $y$ vida sin valor corre el riesgo de ser interpretada no en sentido hedonista en favor del paciente, sino en sentido hedonista en favor de quien debe atenderlo, $o$ aún peor en sentido economicista", como "no rentable para la comunidad" -Ortotanasin: el carácter inalienable del derecho a la vida en Problemas de la eutanasia (cit. nota 9), pág. 53.

39 Günther JAKOBS considera que "una vida que tiene un sentido 'per se', justamente no pierde ese sentido por el dolor, pero sí una vida cuyo fundamento se agota, por falta de un sentido vinculante, en -como sc dice corrientementela calidad de vida"; de ahí que justifique la despenalización en "una sociedad para la cual el dolor siempre carece de sentido y la evitación del dolor siempre lo tiene" -Sobre el injusto del suicidio $y$ del homiridio a petición (cit. nota 30), págs. 27 y 31 . Una argumentación contraria: J.M.BARRIO MAESTRE La eutanasia. Una reflexión antropológica "Cuadernos de Bioética" 1996 (3), págs.277-278. En el debate parlamentario a ERC, sin alusión alguna a cuidados paliativos, aspira a evitar las "situaciones de ilegalidad de aquellas personas que quieren a la persona que desea morir, personas que más que nadic quisieran que viviera, pero que se sienten en la obligación de ayudar a este ser querido a renunciar a una existencia que muchas veces ya no nos atrevemos a calificar de vida". de ahí que invite a no "negar al prójimo los medios necesarios para evitar la indignidad, el dolor y 
el sufrimiento innecesario", partiendo del convencimiento de que "cuando la vida es un sufrimiento, ya no es un derecho, es una obligación y no podemos obligar a las personas a vivir" -(ibidem), pág. 10.904.

40 Johannes RAU élrá todo bien? Por un progreso a escala humana, XII (cit. nota 18), pág. 59. Ronald DWORKIN apunta que "es plausible, y para muchos decisiva, la idea de que la dependencia total es en sí misma algo nefasto"; por lo que "la dependencia total, o casi total, sin nada positivo que la compense, parece que no sólo no agrega nada a la calidad total de una vida, sino que la priva de algo importante" -El dominio de la vida (cit. nota 29), pág. 275. Para J.M.SERRANO RUIZ-CALDERON, por el contrario, "la atención especial a los más dependientes es un factor que define el grado de civilización" -Eutanasia y vida dependiente (cit. nota 38), pág. 147. E.FERNANDEZ GARCIA invita a matizar el "optimismo teórico" de planteamientos liberalizadores de la cutanasia, sin analizar el modo "en cada sociedad concreta, de evitar una manipulación de ese consentimiento o una presión expresa o latente (pero sutil) de la familia, conocidos o de la opinión pública sobre la autonomía personal del paciente", ya que, a su juicio, "la ética de nuestras sociedades desarrolladas $e$ inteligentes no está a la altura del progreso técnico y social alcanzado" -Dignidad humana y eutanasia en Problemas de la eutanasia (cit. nota 9), pág. 44.

41 Günther JAKOBS, defendiendo la despenalización de la eutanasia activa, no duda en admitir que "lo que la mayoría solicita mientras que aún pueda hacerlo de un modo inteligible, forma el estándar conforme al cual se tiene que actuar en caso de duda" -Suicidio, eutanasia y derecho penal (cit. nota 10), pág. 68. Pasajes del debate parlamentario quedan abiertos a interpretaciones varias; ERC enfatiza: "no decimos que nadie deba morir cuando su religión, su ética o sus creencias se lo prohíban", mientras desde Coalición Canaria (en adelante CC) se apunta que "la solución no es facilitar que se provoque la muerte ante la depresión o la desesperación, por muy costosa que sea esta atención" -(ibidem), pág. 10.904 y 10.907.

42 Así lo defiende C.PECES-BARBA MARTINEZ con notable convicción: "en el caso de la enfermedad irreversible tampoco habria vida personal digna de tal nombre, y no sería aplicable la protección que supone el derecho a la vida"; lo que haría constitusionalmente viable la eutanasia, no ya "como consecuencia de un derecho de disposición, sino como un derecho que arranca de la imposible recuperación de la dignidad humana" - $L a$ ettanasia desde la Filosofia del derecho (cit. nota 9), pág. 20.

43 Fn el debate de referencia IU afirma que "morir dignamente y vivir dignamente son las dos caras de una misma moneda" y, partiendo de que "la muerte no es más que un instante del proceso vital, es decir, que la muerte forma parte de la vida" propone "una nueva cultura de la vida con uve-, que nada tiene que ver con la defensa de la vida - con be-", "biologicista" y "primaria", "en la que aspectos como dignidad y libertad están excluidos". La calidad entra en juego: "cuando los seres humanos tienen una vida digna y viven en plenitud de facultades, son capaces de enfrentar la muerte con esa dignidad de la que hablamos". ERC pone en guardia ante "demasiadas interpretaciones cicateras y regresivas de lo que podríamos definir con cl artículo 15 de la Constitución española. Hay que hacer una interpretación con el sentido común". 'lambién IC-FV admite que le gusta más hablar del derecho "a una vida digna que a una muerte digna"; equiparando la dignidad a "una vida consciente, a una vida no vegetal, a una vida autónoma, a una vida sin grandes sufrimientos", y mostrándose a la vez convencidamente optimista sobre la posibilidad de que acabe siendo "la persona libremente quien debe decidir si quiere continuar o no viviendo". Al portavoz de los nacionalistas catalanes de Convergencia i Unió (en adelante CIU) le preocupa "cómo pueden llegar a garantizar los poderes públicos la calidad de 
vida de los ciudadanos en esa etapa final". Para el PSOE "sólo la vida amparada en la libertad y en la dignidad es objeto de reconocimiento constitucional". El portavoz de la mayoría (en adelante PP) no deja por su parte de afirmar que "la muerte no existe. No hay un primer acto de la muerte. Hay un último acto de la vida que hay que ayudar a hacer con dignidad" (ibidem, págs. 10.902-10.903, 10.904, 10.905, $10.909,10.911$ y 10.913$)$.

44 Significativo al respecto el discurso de M.GASCON ABELLAN, que maneja un coneepto de dignidad vineulado al ejercicio de la libertad, que "entroniza el principio de autonomía", y "centra el sistema en torno ala supremacía de la persona", lo que sería a su juicio característico de un "modelo liberal como el que encarna la Constitución española", después de haber aludido a un "estado de indignidad irreversible de la víctima", repetidamente identificado con el dolor, sin llegar, como parecería obligado, a preguntarse si libertad y dolor han de considerarse tácitamente incompatibles -Problemas de la eutanasia "Sistema" 1992 (106), págs. 99, 100 y 82.

45 Resulta significativa la precaución, cuando no un poco disimulado escepticismo, con que médicos especializados, convocados a la Comisión de Estudio planteada en el Senado español durante la VI Legislatura, abordan la fiabilidad de una decisión autónona expresada por anticipado, fuera del contexto de un tratamiento progresivo, o la viabilidad prácticu del llamado "testamento vital". Por referirnos sólo a su primera sesión, cfr. Cortes Generales. "Diario de Sesiones del Senado. Comisión especial de Estudio sobre la Eutanasia" VI I.egislatura, Comisiones $n^{\circ} 307$, de 16 de junio de 1998, págs. 41 y 44, o menos drásticamente: págs. 10,19 y 23 . Sus sesiones se prolongaron hasta el 18 de noviembre de 1999. Frecuentes alusiones a dichas comparecencias en el interesante estudio de J.M.SBRRANO RLIZCAIJERON Eutanasia y vida dependiente, (rii. nota 38), passim.
46 Para CC "no se puede hablar de eutanasia sin antes haberlo hecho de cuidados paliativos", que estimu poco desarrollados "en Holanda, país en cl que está despenalizada la eutanasia"; le parece "incorrecto que, existiendo como existen en España pacientes terminales que no reciben una atención óptima, esta Cámara transmitiese a la sociedad la posibilidad de acelerar la muerte de los pacientes terminales sin poner remedio antes a las careneias asistenciales". También CIU aboga por la "potenciación de los cuidados paliativos", considerando "más positivo profundizar en ellos que entrar en otras consideraciones u opciones más problemáticas". El PSOF los considera necesarios "para configurar una calidad de vida en una democracia avanzada": así como un tipo de actuaciones "que permita la excedencia laboral a aquellas personas que cuidan a familiares en fase terminal" (ibidem, págs. 10.906-10.907, 10.909 y 10.910).

47 IL' considera imprescindibles "garantías y cautelas que impidan que pueda ser violentada la libre decisión de ningún ser humano" y anima a consensuarlas, consciente quizá de la complejidad del empeño. Mientras que ERC aboga de modo más genérico por la necesidad de satisfacer un "deseo contrastado", IC-EV invita a "iniciar un proceso de legalización de la eutanasia activa; un proceso y una iniciativa con todas las garantías que sean precisas para evitar riesgos". 'También, en lo que a garantías se refiere, el PSOE se muestra partidario de "todas las indispensables para que esto se conforme sin abusos". No deja de resultar llamativo que tal problema, que es el propiamente jurídico, parezca quedar aplazado en el debate parlamentario, generoso por el contrario en consideraciones morales. Ello puede explicar que CC reclame "que se adopten medidas oportunas para poderlo ejercer con las debidas garantías. Precisamente por eso no estamos de acuerto ni con el contenido ni con la forma concrela de estas tres proposiciones que hoy debatimos", considerando insuficiente que "a 
posteriori, tras haberse producido el

fallecimiento, se demostrara que las causas están dentro de lo que se propone en la ley" (ibidem, págs. 10.902, 10.904, 10.905, 10.911 y 10.906).

48 'Thomas HOBBES Leviahan or the Matter, Form and Pover of a Commonweallh ecclesiastical and civil I, 15 [71] y I, 11 [50] (traducción al espuñol de M.Sánchez Sarto) Puerto Rico, Ed. Universitaria, 1968 , págs. 125 y $9 \mathrm{l}$.

49 Nada menos que la de lo no-prohibido nopermitido, en la voluntariosa formulación de A.KAUFMANN -Rechtsphilosophie München, C.H. Beck'sche Verlagsbuchhandlung, 1997 $\left(2^{2}\right)$, págs. 226 a 234 . Tras haber dejarlo en múltiples ocasiones sobradas pruebas de mi deuda con su interesante obra, no he dejarlo de criticar tan peculiar propuesta: $E l$ papel de la personalidad del juez en la determinación del derecho. Derecho, historicidad y lenguaje en Arthur Kaufmann "Persona y Derecho" 2002 (47), págs. 319-322.

50 "La frontera de tolerancia de lo originariamente considerado como "normal' se irá difuminando con los acumulativos efectos de acostumbramiento fruto de normas sanitarias más pormenorizadas y de las intervenciones genéticas permitidas" -Die Zukunft der menschlichen Natur. Auf dem Weg zu einer liberalen Eugenik? Frankurt/M., Suhrkamp, 2002 (4 ampliada), págs. 122, 123 y 149.

51 Comienzo indisponible que encuentra tematizado en Hannah Arendt y su concepto de "natalidad" -Jürgen HABF,RMAS Die Zukunft der menschlichen Natur (cit. nota 50). págs. 79 y $158,90,101$ y 144 .

52 J.BALLESTEROS considera que "se absolutiza la autonomía confundiendo la autonomía moral, como principio de responsabilidad personal, que es inobjetable, con la autonomía personal, olvidando que: el ser humano no es sólo autonomía sino también interdependencia" -Ortotanasia: el carácter inalienable del derecho a la vida (cit. nota 38), pág. 52.
53 El Tribunal Europeo de Derecho Humanos, en el caso Pretty (cit. nota 31), considera (epigrafe 74) "vulnerables" a muchas de las personas que sufren una enfermedad en fase terminal; ya que sin una prohibición general del suicidio asistido existen riesgos manifiestos de abuso, lo que la justifica como "necesaria en una sociedad democrática". Ein el debate parlamentario CIli alude a "consecuencias no deseadas, que asimismo existen en aquellos países en los que se ha aprobado una regulación de este tipo" -(ibidem), pág. 10.908.

$54 \mathrm{Al}$ respecto los datos aportados por $\mathrm{Anton}$ van KAL.WTHOOLT - Litanasia, ayuda al suicidio y terminación activa de la vida sin solicitud expresa en los Paises Bajos en El tratamiento jurídico de la eutanasia. Una perspectiva comparada (José Luis Díez Ripollés y Juan Muñoz Sánchez coordinadores), Valencia, tirant lo blanch, 1996, págs. 295 y 318-322. Un detenido estudio, destinado a matizar "una conclusión precipitada: que la supuesta elevada frecuencia de opciones en favor de la eutanasia ha determinado su aceptación social, política, moral y jurídica para el ejercicio de la medicina en aquellas tierras", en J.J.MORA MOI.I.VA Holande: entre la vida y la muerte Valencia, tirant lo blanch, 2002, pág. 15.

\section{Jürgen HABERMAS Die Zukunft der} menschlichen Natur (cil. nota 50), págs. 54-55 y 28. Cünther JAKOBS relativiza los riesgos, al admitir que "conforme a la experiencia, toda libertad se usa para maldades" -Suicidio, eutumasia y derecho penal (cit. nota 10), pág. 49- o que "siempre que se confecciona de modo más amplio el manto de la libertad, también es posible que con mayor facilidad se oculte bajo él la violencia" -Sobre el injusto del suicidio y del homicidio a petición (rit. nota 30), nota 29 de la pág. 31. Fin el debate parlamenturio IC/EV parece relativizar también unos riesgos que no descarta: "el carné de conducir, por ejemplo, es un riesgo. De lo que se trata en este caso es de disminuir los riesgos y podría ser limitando la velocidad de conducir"; también en este caso "hay que decir 
clarísimamente que hay riesgos, que la ley ha de contemplarlos" -(ibidem), pág. 10.905.

56 V.MENDEZ BAIGES ve en ello una invitación a "cierta tolerancia y suavidad en el manejo de los casos concretos, la clandestinidad incluso de algunas prácticas"; a lo que opone tajantemente que "la razón por la que la concesión de ese derecho a morir da tanto miedo es porque obliga a una mayor transparencia social respecto al proceso de morir" y que lo con ello se defiende "no es tanto la situación de ciertas personas especialmente vulnerables como el actual control absoluto y el secretismo de las instituciones sociales" sobre el particular -Sobre morir (cit. nota 33), págs. 86 y 104.

57 No falta en el debate parlamentario la réplica. IU se pregunta "ipara que nos sirve un marco legislativo que ignora la realidad social?"; pero prevé en su proposición la puesta en marcha de Comités de Etica en los centros sanitarios. Mientras ERC propone "mecanismos de total transparencia" que "impiden decisiones aleatorias o no suficientemente claras", IC/liV consideraráa que la remisión a la buena praxis médica supondría aceptar "hipócritamente, el hecho de que hoy se estén realizando prácticas de eutanasia de forma oscura y clandestina"; argumento del que se hace eco $\mathrm{CIU}$ para proponer la necesidad de "plantear alternativas viables a esta práctica mientras se mantenga su prohibición" -ibidem, págs. $10.902,10.904,10.905$ y 10.909.
58 A.M.MARCOS DEL CANO considera que así habría ocurrido en Holanda, donde "parece que las garantías establecidas en la regulación lo son más para proteger al médico que para proteger al paciente" y "el principio de autonomía que se erigía como primer argumento para su justificación, pasa a un segundo plano a favor del principio de calidad de vida" -Legislación eutanásica y realidad social: la experiencia de Holanda en Problemas de la eutanasia (cil. nota 9), pág. 84.

59 Para Ronald DWORKIN "la dignidad de una persona está conectada normalmente, a su capacidad de autorrespeto", lo que le lleva a preguntarse. "ideberíamos ocuparnos de la dignidad de un paciente demente si él mismo no tiene conciencia de su dignidad?" -El dominio de la vida (cit. nota 29), pág. 289; también págs. 306-307. También para G.PEC.ES-BARBA MARTINEZ tanto dignidad como autonomía dependerán de la calidad de vida: "es la vida la que permite la dignidad de nuestra condición y el desarrollo de la personalidad, es decir de todas las virtualidades que hacen posible que cada uno pueda libremente elegir sus planes de vida orientados a conseguir la autonomía o la independencia moral" -La eutanasia desde la Filosofía del derecho (cit. nota 9), pág. 21. 